ISSN: 2238-8052

\title{
PRIVATIZAÇÃO DO ACESSO AOS VENTOS MARÍTIMOS: O CASO DO BAIRRO BOA VIAGEM - RECIFE/PE
}

\author{
PRIVATIZATION OF ACCESS TO MARITIME WINDS: THE CASE OF BOA VIAGEM NEIGHBORHOOD \\ - RECIFE/PE
}

\author{
Arthur Felipe de Melo TEIXEIRA ${ }^{1}$ \\ Armando Peres QUINTAS NETO²
}

Artigo recebido em 02/06/2018 e aceito em 06/08/2018

Palavras-chave: Privatização; Ventos Marítimos; Direito à cidade.

Keywords:

Privatization; Sea Winds; Right to the city.

\section{R E S U M O}

No âmbito da perspectiva do processo de produção do espaço, os elementos naturais, enquanto bens públicos aos quais todos e todas devem ter direito, em vários momentos da história urbana das cidades, não são considerados e incluídos em ações de planejamento territorial permitindo a promoção da qualidade de vida para as pessoas. Seguindo esta lógica, o bairro Boa Viagem, localizado na zona sul-sudeste do município de Recife/PE, vem sendo produzido, ao longo de décadas, com base num modelo de expansão prioritariamente vertical ao longo da faixa costeira. 0 objetivo deste trabalho consiste na elucidação da questão do acesso aos ventos marítimos, correlacionando-o com o processo de produção do espaço realizado em Boa Viagem. O que foi realizado através de uma revisão bibliográfica, bem como de interpretação de representações cartográficas produzidas no software Arcgis 10.2 e entrevistas. Os principais resultados chamam nossa atenção para a inexistência de preocupação por parte do poder público no que se refere ao controle da ocupação do espaço no bairro, bem como para a constatação da privatização dos ventos marítimos.

\begin{abstract}
A B S T R A C T
Within the perspective of the space production process, natural elements as public goods to which all people must have right, throughout urban history of cities, are not took in consideration and included in territorial planning actions allowing the promotion of the life quality. Following this logic, the Boa Viagem neighborhood, located in the southsoutheast zone of the Recife-PE municipality, has been produced, during decades, based on a model of vertical expansion mainly along the coastal strip. The objective of this work is to elucidate the issue of access to sea winds, correlating it with the space production process carried out in Boa Viagem. This was done through a bibliographical review, as well as interpretation of cartographic representations produced in the Arcgis 10.2 software and interviews. The main results point to the absence of concern on the part of the public power regarding the control of the occupation of space in the neighborhood studied, as well as to the privatization of the sea winds.
\end{abstract}

\footnotetext{
${ }^{1}$ Graduando em Bacharelado Geografia - UFPE. E-mail: ameloteixeira23@gmail.com.

${ }^{2}$ Licenciado e bacharelando em Geografia pela Universidade Federal de Pernambuco - UFPE. Especialista e Análise ambiental pela Universidade Federal do Paraná - UFPR. E-mail: armando-peres@hotmail.com.
} 


\section{INTRODUÇÃO}

Em tempos passados, os ventos marítimos foram considerados e apreciados como um bem coletivo, cujo uso deveria contemplar o interesse de toda a sociedade. No entanto, atualmente, baseado no sistema capitalista de produção, na sua faceta de produção do espaço, os ventos marítimos tornaram-se mercadorias, ou melhor, um elemento a ser acrescido ao valor final dos imóveis que se expandem na cidade sobe a lógica do processo de valorização puramente econômica do espaço urbano.

Fruto de uma pesquisa do Projeto de Iniciação Científica (PIBIC), financiado pela Fundação de Amparo à Ciência e Tecnologia de Pernambuco (FACEPE) no período de agosto de 2016 a julho de 2017, o presente artigo buscou ressaltar a problemática do acesso ao elemento natural ventos marítimos, correlacionando-os com o processo de produção do espaço realizado no bairro Boa Viagem, Recife-PE.

Conforme Magarotto (2012), após a construção da avenida Boa Viagem, realizada em meados de 1920, o bairro de Boa Viagem passou a ser visto como um espaço propício para o lazer e o turismo. O autor ainda ressalta que, em cinco décadas, desde, então, 1920, o bairro passou de um local de veraneio para tornar-se uma área residencial, posteriormente verticalizada e, por conseguinte, densamente povoada.

De acordo com Costa et al., (2008), a verticalização da orla de Boa Viagem, assim como das áreas circunvizinhas, foi acontecendo de maneira rápida e sem controle, seguindo a opção arquitetônica das classes hegemônicas locais. E isto, sem nenhum controle em termos de planejamento para produção do espaço, o que impactou visivelmente na circulação do ar dentre outros fatores relevantes para a manutenção do conforto ambiental local.

Contrapondo-nos a este modelo de produção do espaço, nossa preocupação fundamentou-se na perspectiva dos ventos marítimos como um bem comum a todos e todas, diferentemente da perspectiva mercadológica que defende a privatização deste elemento natural visando incrementar o valor final dos edifícios construídos na sua direção, ou seja, voltados para a nascente. Como consequência desta lógica de produção do espaço urbano:

[...] os calores desconfortáveis, na maioria dos lugares e na maior parte do ano, tornam-se uma questão de diferença entre bairros, entre dois lados da mesma rua [o voltado para o nascente e o voltado para o poente] ou entre horas do dia [as da manhã e as da tarde]. Acresce que, ao longo da orla litorânea, a exposição mais direta aos ventos, impedindo que se sinta verdadeiro calor em qualquer hora e em qualquer época, constitui um dos fatores mais importantes da preferência, por parte de parcela cada vez maior da população, pela faixa marinha como área residencial. Área que se estende linearmente, em sua parte urbanizada (MELO, 1978, p. 39-40).

No entanto, dentre os princípios relevantes ao respeito e à garantia do acesso à natureza de maneira equilibrada, encontra-se, fazendo parte da Constituição da República Federativa do Brasil, o: 
Art. 225. Todos têm o direito ao meio ambiente ecologicamente equilibrado, bem de uso comum do povo e essencial à sadia qualidade de vida, impondo-se ao Poder Público e à coletividade o dever de defendê-lo e preservá-lo para as presentes e futuras gerações.

$\S$ 1을 Para assegurar a efetividade desse direito, incumbe ao Poder Público: I - preservar e restaurar os processos ecológicos essenciais e prover o manejo ecológico das espécies e ecossistemas; [...]

IV - exigir, na forma da lei, para instalação de obra e atividade potencialmente causadora de significativa degradação do meio ambiente, estudo prévio de impacto ambiental, a que se dará publicidade; [...].

$\S 3^{\text {o }}$ As condutas e atividades consideradas lesivas ao meio ambiente sujeitarão os infratores, pessoas físicas ou jurídicas, a sanções penais e administrativas, independentemente da obrigação de reparar os danos causados... (BRASIL,1988).

Em assim sendo, percebe-se a tendência que se foi consolidando no tempo da história urbana local, privatizando, também, o uso dos ventos marítimos, garantindo-os como direito apenas para quem pode pagar para morar nos prédios localizados diante dos ventos e negando este direito aos demais, ou seja, àquelas classes sociais mais pobres que se localizavam há décadas nas áreas onde hoje se levantam os altos edifícios.

Em Boa Viagem, a apropriação dos terrenos com melhor qualidade em termos de habitação ocorreu por parte dos setores sociais mais abastados. Alinhado a este fato houve, de forma acelerada, a verticalização da orla marinha e a expulsão de famílias pobres das áreas próximas à praia. Tais famílias, com menor poder aquisitivo, passaram a habitar às margens dos rios que cortam a cidade (MAGAROTTO, 2012).

Neste sentido, nota-se claramente que a construção de tais assentamentos, no curso da história urbana em Recife, tem que ser vista mais como uma solução encontrada pelos pobres para superarem a escassez de habitação na cidade do que como um problema. Muito embora, as classes sociais hegemônicas locais sempre tenham percebido a construção de tais assentamentos como problema, fundamentando seu interesse de removê-los do caminho dos fluxos do capital e promover a produção do espaço baseada, sobretudo, na verticalização.

Hoje, parte significativa do território em epígrafe continua sendo ameaçada pelos interesses alienígenas e alienadores do espaço, cujo objetivo de verticalizar a cidade é passado, através de um discurso capitalista, como algo comum nos tempos modernos, sendo assim necessário para o desenvolvimento local. Desta maneira, nesta pesquisa, refletiu-se, principalmente, sobre o sentido da apropriação - "privada" - da natureza em ações urbanísticas, no bairro de Boa Viagem, a partir do uso dos ventos marítimos, bem como identificar a lógica dos principais atores envolvidos neste processo de produção do espaço urbano, além de buscar entender quem de fato tem conseguido garantir o direito de se manter ao menos próximo a este elemento. 


\section{LOCALIZAÇÃO E CARACTERIZAÇÃO DA ÁREA DE ESTUDO}

O bairro de Boa Viagem, localizado na zona sul-sudeste da cidade de Recife-PE (Figura 1), possui, de acordo com o Instituto Brasileiro de Geografia e Estatística-IBGE (2010), 112.922 habitantes (aproximadamente 8\% da população de Recife), distribuídos numa área de 8,4 km² de extensão e compõe, junto a outros bairros, um dos recortes com o metro quadrado mais caro da capital pernambucana.

Figura 1. Mapa de Localização do Bairro Boa Viagem, Recife-PE.

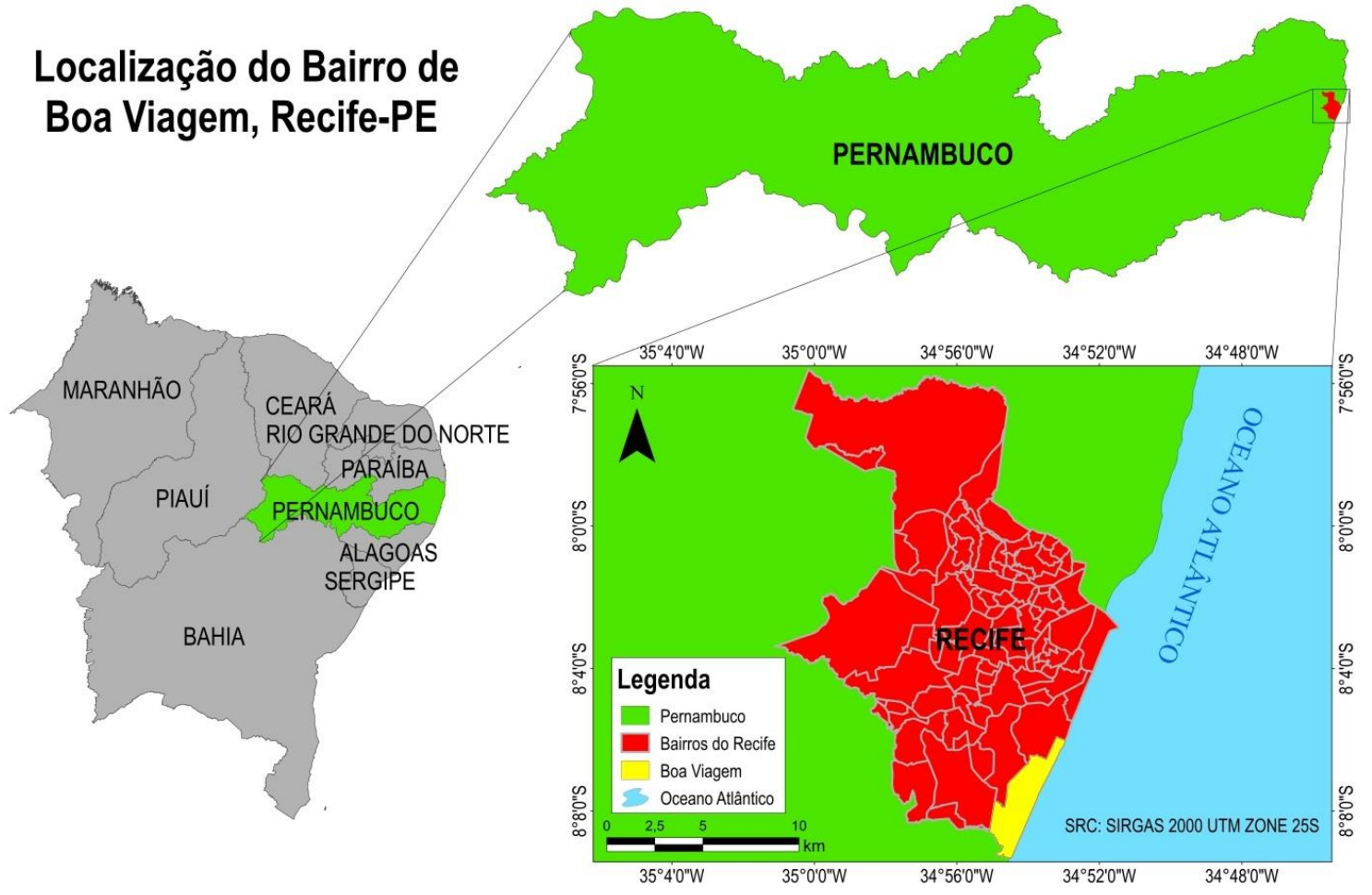

Fontes de dados: Prefeitura do Recife (2017) e Ministério do Meio Ambiente (2007).

Organização: Arthur Teixeira (2017).

Esta área faz limites com os bairros do Pina (Norte), Imbiribeira e Ibura (Oeste) e Piedade (Sul), este último pertencente ao município de Jaboatão dos Guararapes, além do Oceano atlântico (Leste). 0 recorte conta com aproximadamente $8 \mathrm{~km}$ de linha de costa, representada pela Praia de Boa Viagem.

A cidade de Recife, na qual o bairro Boa Viagem está inserido, segundo Ferreira (2016), conforme a classificação de Köppen, possui o clima tropical úmido com temperaturas médias que, nos períodos mais frios, ultrapassam os $18^{\circ} \mathrm{C}$. 
Ainda segundo o autor supracitado, a cidade do Recife possui como principais sistemas atmosféricos secundários causadores de chuvas na região os Distúrbios Ondulatórios de Leste, os Vórtices Ciclônicos de Altos Níveis, a Zona de Convergência Intertropical, a Zona de Convergência do Atlântico Sul e os Sistemas Frontais. 0 índice pluviométrico da cidade, que influem na área em análise, gira em torno de $1600 \mathrm{~mm}$ anuais.

Ocasionada pela forma de produção e apropriação do espaço ao longo de décadas, como ressaltado acima, praticamente inexistem exemplares e espaços remanescentes do ecossistema manguezal que deveria estar presente na área em estudo (COSTA et al., 2008).

Com isto, Boa Viagem, que, em outros momentos da história urbana da cidade, reunia pescadores e fazendas de coqueiros, possui hoje uma área habitada, sobretudo, por setores das classes hegemônicas pernambucanas, tomada pela urbanização verticalizada, muito embora não tenha deixado de receber projetos desenvolvimentistas de ordem pública e privada (SILVA, 2007).

\section{3. $O$ CLIMA URBANO E A VERTICALIZAÇÃO NO BAIRRO DE BOA VIAGEM}

Para Lima et al., (2011), o clima, diante de seus fatores e elementos, deve ser considerado como uma das dimensões do ambiente urbano, isto na tentativa de reunir mecanismos que auxiliem a compreensão das questões ambientais do espaço urbano. Ou seja, deve-se considera-lo para o planejamento e desenvolvimento do espaço como especificidade do sítio geográfico, somado as outras variáveis ambientais existentes na área.

Ribeiro (1993), sobre a definição do clima e seus elementos, afirma que:

o clima é regido por um conjunto integrado de fenômenos que se fundem no tempo e no espaço, revelando uma unidade ou tipo passíveis de serem medidos em seu tamanho (extensão) e em seu ritmo (duração). 0 fenômeno climático é constituído por um conjunto de elementos de naturezas diversas e que convivem ao mesmo tempo no mesmo espaço, em regime de trocas energéticas reciprocas e interdependentes. (RIBEIRO, 1993, p.288).

Acerca da importância do clima, sua interação com o homem e os efeitos dessas interações na escala local e global, Nóbrega e Lemos (2011) coloca que:

O clima exerce influência sobre o homem, assim como o homem também desempenha um papel importante na dinâmica climática através de suas várias atividades. Se a sociedade influi no clima em escala global isso ainda é alvo de muita discussão entre os inúmeros cientistas, entretanto parece ser unânime que o homem seja capaz de alterar o clima em escala local. E uma das áreas mais afetadas é a cidade. (NÓBREGA, 2011, p.94).

O clima urbano considera, portanto, todas as alterações causadas por uma ordem antrópica, seja ela benéfica ou não para o ambiente da cidade. Segundo Monteiro (1991), a cidade possui um caráter de espaço de uma contínua, cumulativa e acentuada derivação antrópica do ambiente, tendo, assim, implicações diretas na atmosfera. 
Ainda no âmbito desta perspectiva, este mesmo autor destaca que o clima urbano pode ser caracterizado como um sistema aberto, ou seja, um sistema em que ocorre inputs e/ou outputs de energias, a partir das transformações ocorridas no ambiente, que podem, a considerar suas dimensões e expressões dentro do território, ser externalizadas para ambientes vizinhos.

Dumke (2007) coloca que dentre os mais diversos e nítidos impactos socioambientais sofridos como consequência da produção do espaço, ou seja, intensas transformações realizadas no sítio, encontrasse o que o autor chama de "contaminação e a formação de um clima urbano específico".

Segundo Higueras (2013), um dos possíveis mecanismos para a gestão urbana que busca a qualidade socioambiental no espaço intra-urbano, traduzida posteriormente de forma benéfica no clima urbano, seria a prática do urbanismo bioclimático, expressão utilizada para retratar a forma de produção de espaço que sugere o seguimento de critérios e, sobretudo, as especificidades do território, com o objetivo principal de preservar e proporcionar melhor qualidade de vida para todos os seres inseridos no espaço.

No entanto, sobre a importância e utilização das práticas desenvolvidas a partir de estudos da climatologia urbana, Assis (2005) ressalta que:

Embora se reconheça atualmente a importância da climatologia urbana para o planejamento e a preservação da qualidade ambiental do meio urbano, sua aplicação às atividades de planejamento e projeto das cidades ainda é muito limitada, em parte devido à uma abordagem fragmentada e desintegrada entre os diversos campos do conhecimento envolvidos, em parte devido ao fato de que a grande maioria dos trabalhos nessa área, tanto no Brasil como no exterior, são descritivos e, portanto, seus resultados ficam restritos ao caso em estudo (ASSIS, 2005, p.93).

Então, para a compreensão do chamado clima urbano é necessário que se correlacione as imposições naturais dispostas no sítio com a lógica construcional desenvolvida no ambiente, tendo assim um panorama de entendimento das transformações do sistema natural, neste caso a circulação e o acesso aos ventos marítimos, pela ordem de produção antropogênica na cidade.

Entretanto, se observada a morfologia quase que aplainada da área do bairro de Boa Viagem e a forma de produção do espaço desenvolvida ao longo das últimas décadas, é possível notar a contradição e negação dos fatores naturais em detrimento das formas de apropriação do capital inserido no bairro, principalmente expresso pela especulação imobiliária de alto padrão traduzida pela verticalização.

Conforme Ramires (1998), a verticalização não deve ser enxergada como uma consequência natural do processo de urbanização, pois esta forma de construção retrata uma das opções traçadas, definida e consequentemente expandida pelos atores sociais, norteados pelos interesses de aplicação do capital, nas suas mais diversas facetas do contexto local.

Pereira (2001) coloca que o norte para a produção do espaço urbano se baseia na procura por um maior benefício possível. Então, se apropriando da busca do que a autora chama de 'máximo benefício', o capitalismo, na sua dimensão da produção do espaço imobiliário, promove a valoração do 
solo, elemento que é tratado na Constituição Federal como bem comum a todos e todas. Ainda segundo a autora, os demais elementos da cidade são incorporados nesta lógica de valoração, tendo seu preço atrelado à lei de oferta-demanda.

Desta maneira, apenas as pessoas mais abastardas conseguem atingir o 'máximo benefício', assim como o conjunto de elementos naturais e artificias inclusos neste pacote promovido pelo sistema capitalista de produção.

Dentro desta perspectiva, Silva (2008) contribui com a análise da quebra com a identidade entre os seres humanos e o lugar, causada, neste caso específico, pelo processo de verticalização, no momento em que:

Essa promoção diferenciada de espaços edificados gera uma migração intra-urbana impulsionada pela valorização imobiliária de setores da cidade que tem substituído seus antigos moradores por novos residentes de renda distinta, isso porque quando uma área se valoriza, a população residente se retira, dando lugar à população de uma classe social mais abastada. (SILVA, 2008, p.17).

Desta forma, como nas mais diversas áreas das cidades brasileiras, o bairro em epígrafe, conforme apresentado nas Figuras 2 e 3, retrata esta forma de produção e reprodução do espaço urbano que, ainda conforme o autor acima, representa uma revolução na forma de se construir e reconstruir o espaço urbano, afetando a dinâmica do capital na cidade.

Figura 2. Comunidade Entra Apulso, localizada em Boa Viagem-Recife/PE, "encurralada” por edifícios.

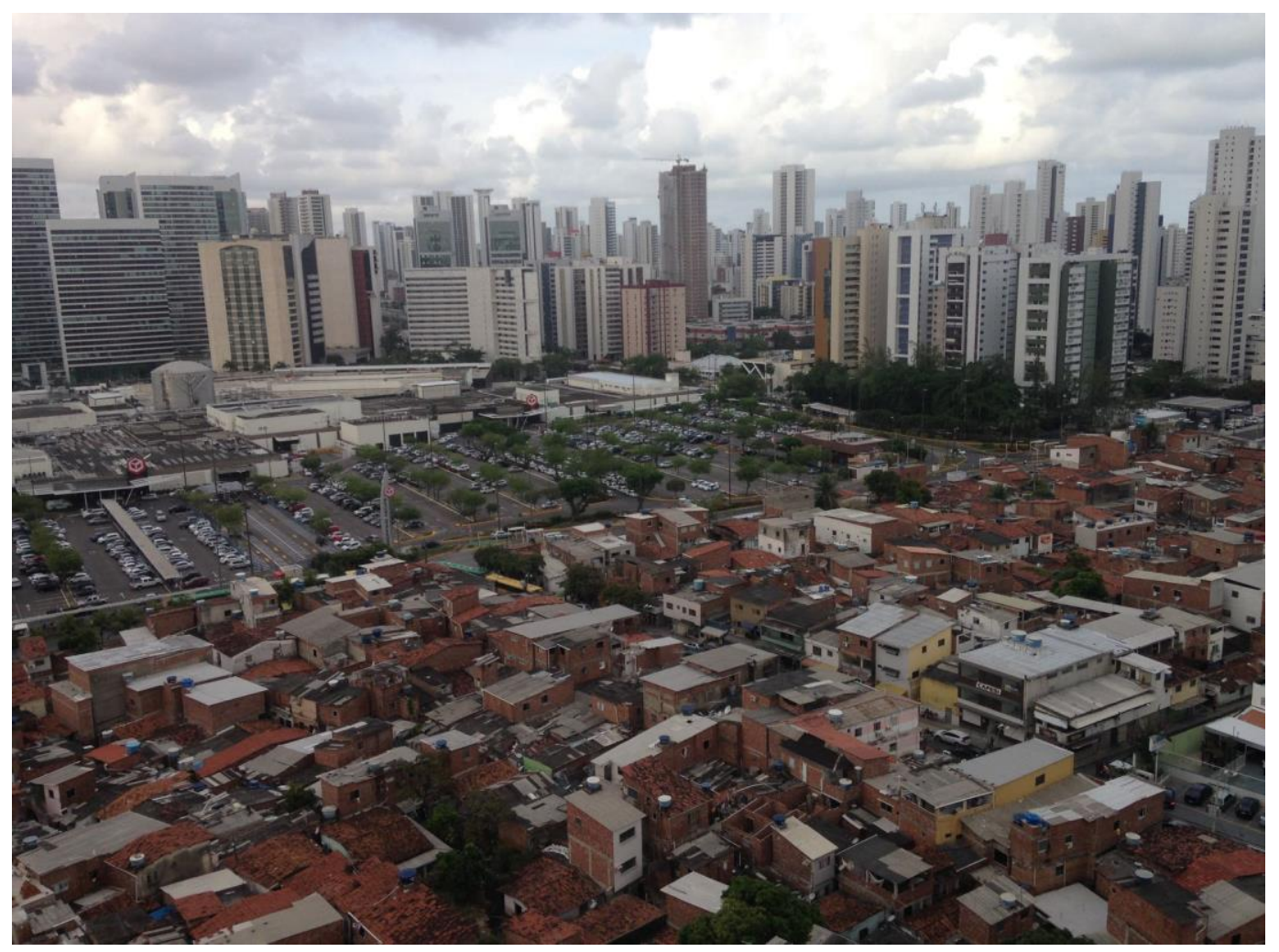

Créditos: Arthur Teixeira, 2017. 
Figura 3. Barreira antrópica no bairro Boa Viagem-Recife/PE.

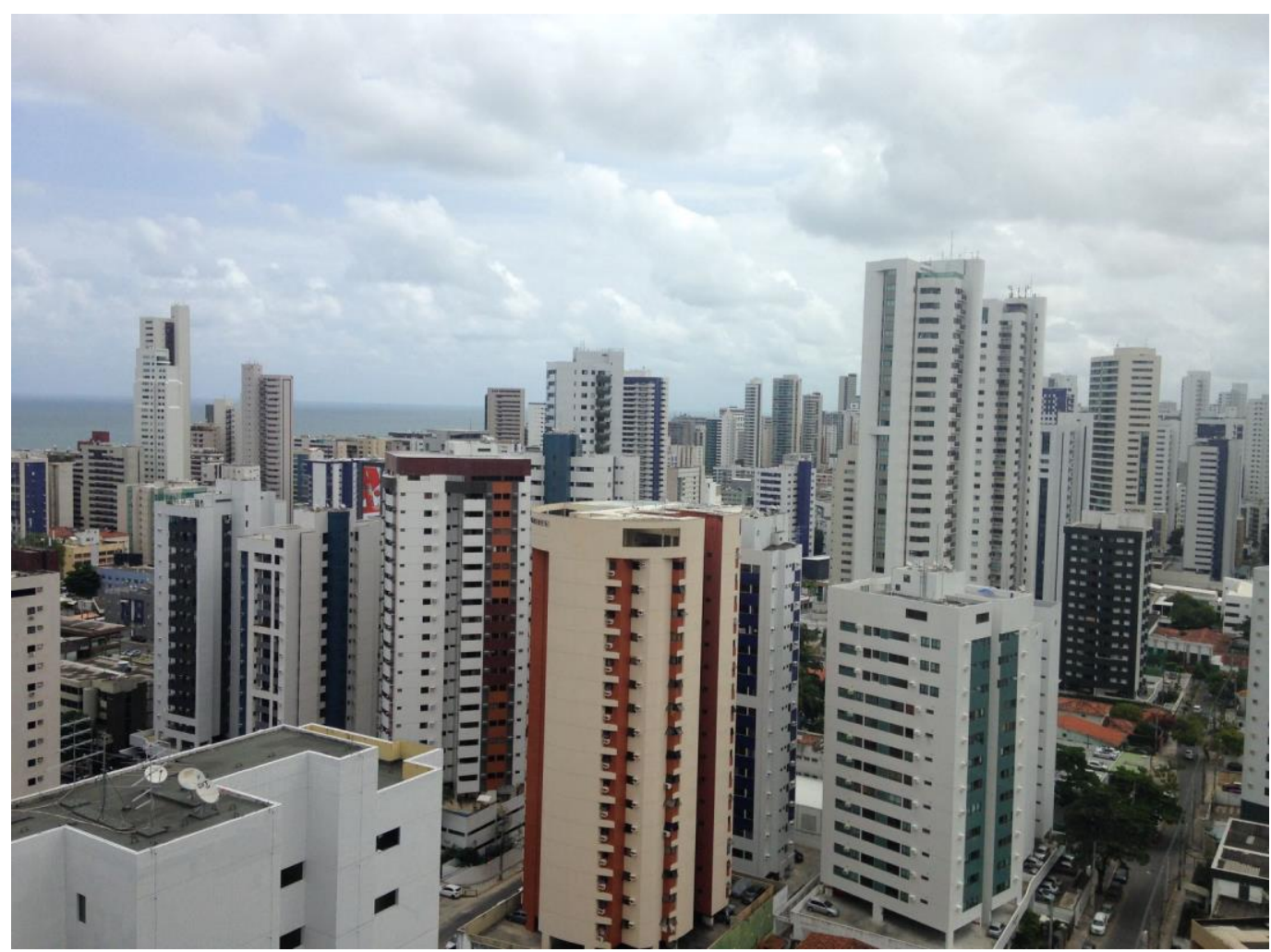

Créditos: Arthur Teixeira, 2017.

Assim, para Boa Viagem especificamente, a especulação imobiliária e as ações de seus respectivos agentes, traduzidas pela verticalização (multiplicação de pavimentos), não representa somente uma maneira de reprodução do espaço urbano de forma aleatória, pois deixa nítida a contradição, desigualdade e privatização de acesso aos elementos naturais, dentre eles os ventos marítimos.

\section{MATERIAIS E MÉTODOS}

Como a realidade ambiental, inerente ao processo de produção do espaço urbano, é diferenciada, a presente pesquisa será realizada com base no Paradigma da Complexidade, o qual:

[...] pede para pensarmos nos conceitos, sem nunca dá-los por concluídos, para quebrarmos as esferas fechadas, para restabelecermos as articulações entre o que foi separado, para tentarmos compreender a multidimensionalidade, para pensarmos na singularidade com a localidade, com a temporalidade, para nunca esquecermos as totalidades integradoras. [...] A totalidade é, ao mesmo tempo, verdade e não-verdade, e a complexidade é isso: a junção de conceitos que lutam entre si. (MORIN, 2000, p. 192).

Assim, partimos do pressuposto que o problema relativo à redução da função dos ventos marítimos no bairro de Boa Viagem não é algo isolado do contexto histórico do processo de produção 
do espaço urbano local. Mas tem tudo a ver com a evolução das formas de uso do espaço pela sociedade brasileira, visando ao atendimento de intencionalidades inerentes ao capitalismo.

Desta maneira, com o intuito de elucidar a problemática da privatização dos ventos marítimos no bairro de Boa Viagem, tendo como caminho a interdisciplinaridade de métodos e formas de análises, foram realizados três procedimentos metodológicos visando à compreensão da temática abordada.

0 primeiro procedimento refere-se à revisão bibliográfica que se encontra nos segmentos iniciais do trabalho, cujo objetivo consistiu em reunir um arcabouço teórico acerca da temática aqui discutida, buscando, assim, um suporte para o entendimento da compreensão da problemática ora delimitada no espaço intra-urbano em epígrafe. Então, a partir da reunião da literatura existente frente ao tema por ora discutido, foi possível fundamentar e compreender a complexidade de todo processo de privatização dos ventos marítimos realizado na cidade do Recife, bem como elencar os principais atores, hegemônicos e não-hegemônicos, que disputam, delimitam e produzem o espaço in loco.

Após esta primeira fase foi realizada a reunião dos dados referentes à parte que compreende o geoprocessamento utilizado na presente pesquisa, tendo como base o arquivo vetorial, no formato shapefile, de bairros do Recife e os arquivos matriciais (imagens) das décadas de 70 e 80 do século XX (ortofotos), além da imagem aérea dos anos 2000 com escala 1:15.000, ambos insumos disponibilizados pela CONDEPE/FIDEM e o Instituto Pelópidas Silveira, órgãos da prefeitura do Recife.

De forma sequencial, com a utilização da licença estudantil gratuita do software de geoprocessamento Arcgis 10.2, foi realizada a segmentação cartográfica do bairro e dos demais bairros de Recife com o recurso da ferramenta clip, a partir do arquivo shapefile de bairros do Recife disponibilizado pelo Instituto Pelópidas Silveira. Em seguida, foram feitos recortes dos dados matriciais, mais precisamente as ortofotocartas das décadas de 70 e 80 do século XX, além da imagem aérea dos anos 2000, tendo como limite vetorial a delimitação do bairro Boa Viagem.

Por fim, foram realizadas entrevistas com os chamados grupos socialmente "excluídos" (CORREIA, 1995) ou, como preferimos, das classes precariamente incluídas, trazendo esta adaptação por entender que nenhuma classe social é integralmente excluída da sociedade, possuindo, assim, algum vínculo por meio de segmentos até mesmo do capital, reforçando ainda mais o estado de desigualdade territorial das cidades brasileiras.

As entrevistas semiestruturadas foram realizadas com moradores de territórios de Boa Viagem que foram removidos para o Conjunto Habitacional Via Mangue II, construído pela Prefeitura do Recife a partir do ano de 2001 com a premissa de "realocar" populações ribeirinhas que moravam por onde hoje passa a Via Mangue. 
Ou seja, trata-se de uma parcela da população que ainda desfrutava do acesso aos ventos marítimos que circulam pelas "marés" dos canais fluviais que cortam a cidade do Recife e que tiveram que deixar seus territórios, muitos deles próximos aos ambientes de trabalho e prestação de serviço utilizado por esta população, com base no discurso de desenvolvimento e mobilidade urbana.

\section{RESULTADOS E DISCUSSÃO}

Com o desenvolvimento do presente trabalho foi possibilitado o entendimento e a reunião de pesquisas sobre os problemas socioambientais traduzidos como consequências da verticalização presente em Boa Viagem, além promover o debate entre conceitos importantes para permitir a compreensão da complexidade encontrada na área em estudo.

Desta forma, o primeiro resultado da pesquisa, exposto nos tópicos iniciais do presente artigo, revelou-se que a temática vem sendo discutida em diferentes esferas acadêmicas por conta das externalizações advindas da forma de produção do espaço em vigência.

Além disto, por meio do geoprocessamento realizado no Arcgis 10.2, tornou-se nítida a evolução da expansão da produção do espaço, concomitantemente com a verticalização no bairro em destaque, seja no sentindo norte-sul, acompanhando a linha de costa, seja no sentido leste-oeste, como representado nas Figuras 4, 5 e 6.

Estas figuras deixam bastante clara a forma de produção do espaço realizada em Boa Viagem, a qual, por sua vez, aconteceu de maneira a promover a "expulsão branda", isto é, aquela cujo objetivo é alcançado pela ocupação do espaço por parte das classes hegemônicas, em detrimento da perda de espaço por parte das classes pobres da sociedade. 
Figura 4. Representação Cartográfica do bairro Boa Viagem, Recife/PE - 1975.

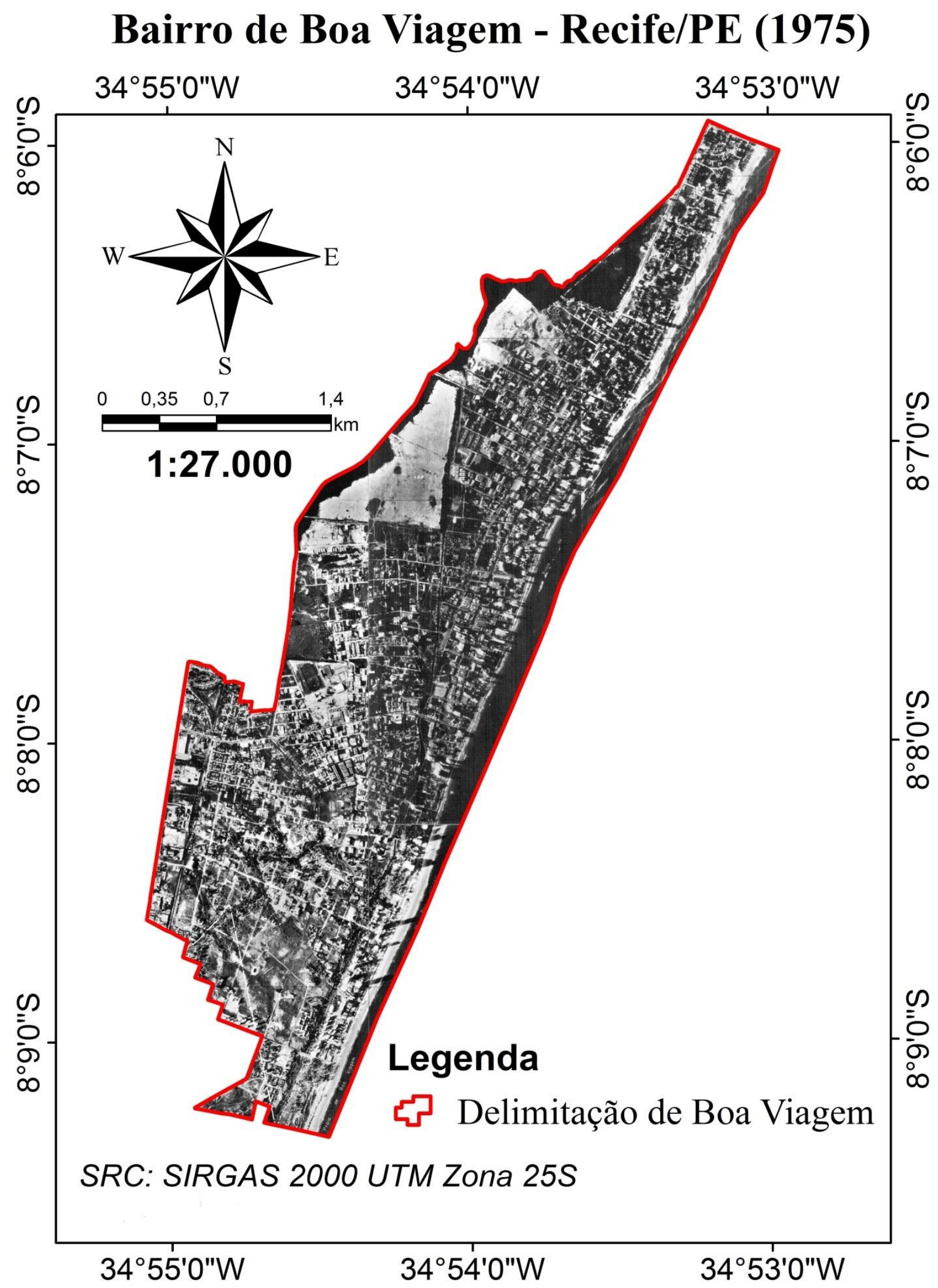

Fonte: Prefeitura do Recife (2017). Organização: Arthur Teixeira (2017). 
Figura 5. Representação Cartográfica do bairro Boa Viagem, Recife-PE - 1986.

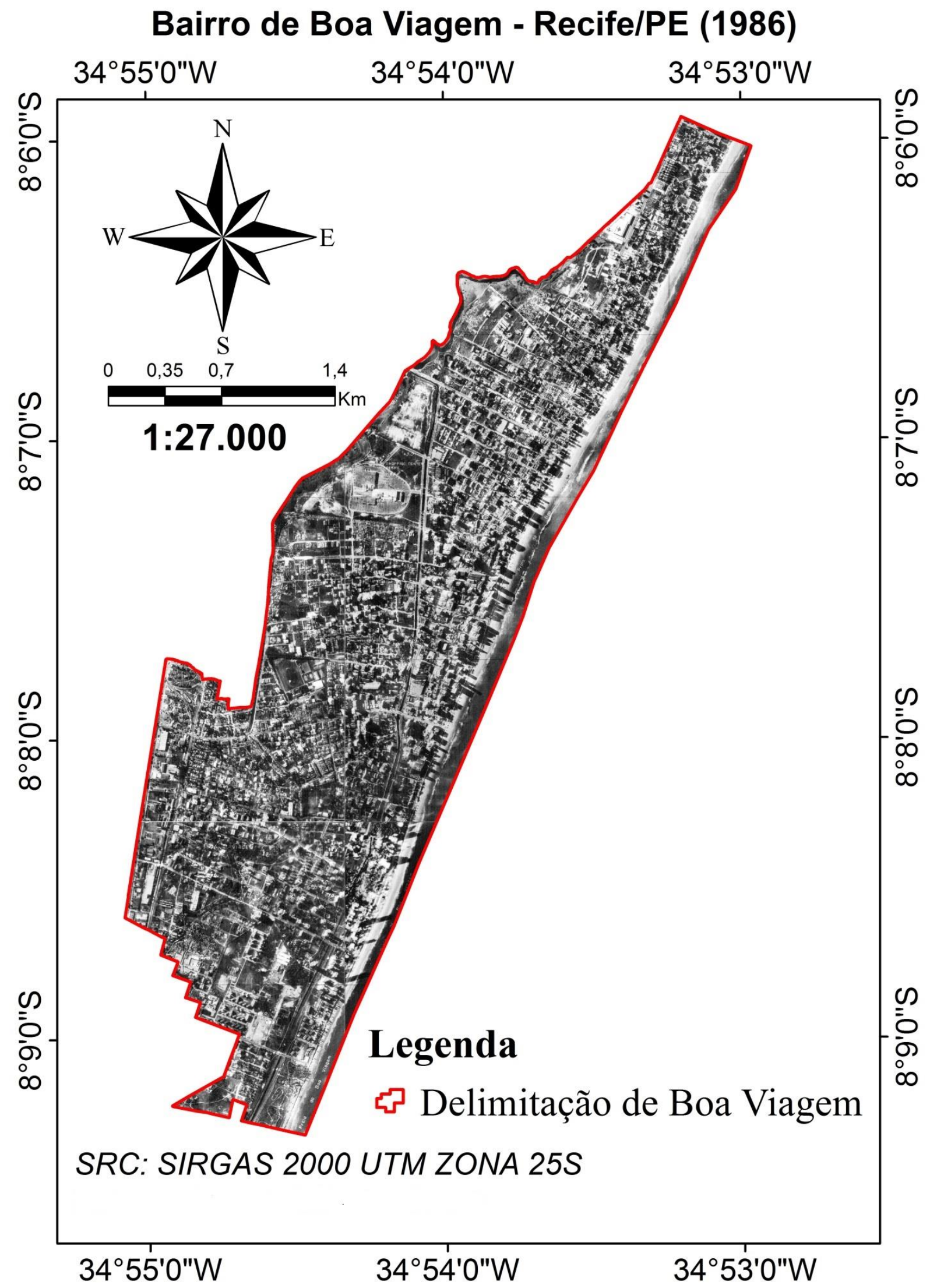

Fonte: Prefeitura do Recife (2017). Organização: Arthur Teixeira (2017). 
Figura 6. Representação Cartográfica do bairro Boa Viagem, Recife/PE - 2013/2014.

\section{Bairro de Boa Viagem - Recife/PE (2013-2014)}

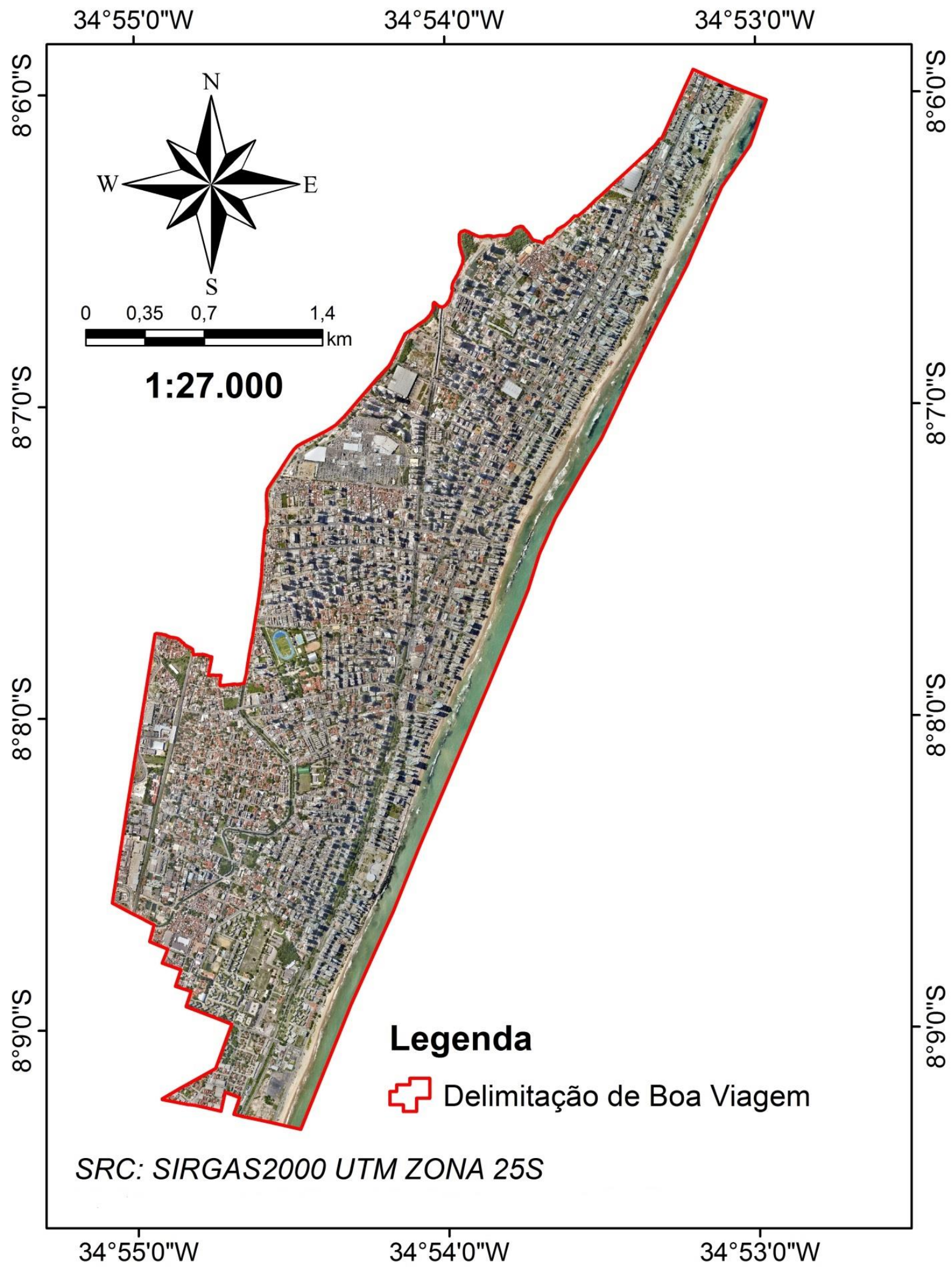

Fonte: Prefeitura do Recife (2017). Organização: Arthur Teixeira (2017). 
O último resultado obtido com a pesquisa refere-se ao acesso a informações sobre o problema através da realização de entrevistas com moradores do Conjunto Habitacional Via Mangue II (CHVMII), localizado no bairro Pina. O CHVMII foi construído com intuito de realocar famílias ribeirinhas que residiam anteriormente em espaços vividos de Boa Viagem. Esta intervenção foi realizada com a premissa da construção da atual Via Mangue, projeto viário que liga a zona sul da cidade do Recife ao centro, o qual, como todos os outros, seguindo a lógica do urbanismo higienista, sempre retiraram as famílias pobres da área.

No entanto, ao se realizar a remoção dessas famílias realocando-as para o CHVMII, pensou-se apenas na provisão da habitação, desconsiderando a complexidade das famílias em termos das suas condições de habitabilidade, como é comum em outros conjuntos da cidade. Além disto, constatou-se que tais ações urbanísticas desenvolvidas pelo Estado tiveram como objetivo facilitar o acesso aos terrenos urbanos de maior valor, fomentando, ao mesmo tempo, a privatização dos elementos naturais ali presentes, como, por exemplo, os ventos marítimos.

A escuta das pessoas revelou, ainda, que cerca de $90 \%$ dos entrevistados, consideram que os dias atuais estão mais quentes se comparados com aqueles de tempos passados, isto numa amostragem de 20 residências visitadas. Somado a isto, como principal causa deste efeito, foi colocado por parte dos moradores que a verticalização, presente na cidade do Recife como um todo, influencia na circulação dos ventos, ocasionando o desconforto térmico sentido atualmente.

\section{CONSIDERAÇÕES FINAIS}

Com base nos resultados da pesquisa ora relatada, a revisão bibliográfica reuniu visões de diversos autores acerca da problemática dos ventos marítimos, da construção do espaço urbano e de suas consequências no clima urbano local, demonstrando que a temática já foi discutida anteriormente e que, aos poucos, vem tornando-se fonte de novos estudos. Isto, sobretudo, porque ainda não se conseguiu resolver os problemas já anunciados outrora.

Com a realização da delimitação e do recorte das imagens no Arcgis 10.2, foi constatada a expansão da barreira vertical que se prolonga em todos os sentidos em Boa Viagem. Assim, a partir do entendimento da perspectiva do clima urbano, enquanto produto social, surge a necessidade de levarse em conta os elementos da natureza no que tange ao processo de construção do espaço urbano sob os parâmetros, por exemplo, de um "urbanismo bioclimático".

Então, após a aplicação das entrevistas, o direcionamento tomado para os questionamentos realizados conseguiu clarificar o problema ora destacado. Isso para explicar as consequências principais de mais esta injustiça que acomete as populações mais pobres que se encontram nas periferias das nossas cidades. Neste caso especificamente, não se tratando da periferia geométrica, 
mas da periferia social, onde se considera a exclusão e falta de acesso aos bens - tornados meros recursos econômicos - como, no caso dos ventos marítimos que são considerados essenciais para a qualidade de vida para todos e todas na cidade.

Contudo, é necessário que haja preocupação por parte da sociedade como um todo - e em especial do Estado - com relação à ordem construcional desempenhada em Boa Viagem, bem como na cidade do Recife como um todo, pois o modelo atual retira mais direitos, como o referente ao acesso aos ventos marítimos, privatizando este bem, tal como ocorre sob o sistema capitalista de produção.

\section{AGRADECIMENTOS}

À Fundação de Amparo à Ciência e Tecnologia de Pernambuco (FACEPE), pela Bolsa de Iniciação Científica concedida para Arthur Felipe de Melo Teixeira; bem como ao Prof. Cláudio Jorge Moura de Castilho pelas instruções e contribuições feitas durante toda trajetória desta pesquisa.

\section{REFERÊNCIAS}

ASSIS, Eleonora Sad. A abordagem do clima urbano e aplicações no planejamento da cidade: reflexões sobre uma trajetória. In: ENCAC-ELACAC 2005 Encontro Nacional de Conforto no Ambiente Construído, Encontro Latino Americano de Conforto no Ambiente Construído, 5-7 out. 2004, Maceió. Anais do... Maceió: ENCAC-ELACAC, 2005.

CORREA, Roberto Lobato. O Espaço Urbano. São Paulo: Ática, 1995.94p.

COSTA, M. F.; ARAÚJO, M. C. B.; CAVALCANTI, J. S. S.; SOUZA, S. T. Verticalização da Praia da Boa Viagem (Recife, Pernambuco) e suas Consequências Sócio-Ambientais. Revista de Gestão Costeira Integrada, v. 8, n. 2, p. 233-245, 2008.

FERREIRA, F.F. Climatologia da Precipitação na Cidade do Recife. In: CONGRESSO TÉCNICO CIENTÍFICO DA ENGENHARIA E DA AGRONOMIA - CONTECC, Foz do Iguaçu, 2016.

HIGUERAS, E. Urbanismo bioclimático. Madrid: Editorial Gustavo Gili, 2013. 242p.

INSTITUTO BRASILEIRO DE GEOGRAFIA E ESTATÍSTICA. Censo Demográfico 2010. Disponível em: <https://sidra.ibge.gov.br/home/ipca15/brasil> . Acesso em: 11/01/2018

LIMA, L. C.ZANELLA, M. E. A climatologia aplicada ao planejamento urbano e ambiental de Aquiraz/CE-BR. Revista Geografica da America Central, v.2, p. 1-13, 2011

MAGAROTTO, M. G. Sistemas de Informação Geográfica Orientados para o Ordenamento do
Litoral. O caso da boa viagem - Recife - PE Brasil. Dissertação de Mestrado em Gestão do Território - Faculdade de Ciências Sociais e Humanas, Universidade Nova de Lisboa. 2012. $113 f$.

MELO, M. L. de. 1978. Metropolização e subdesenvolvimento. $O$ caso do Recife. Recife: Editora da Universidade Federal de Pernambuco.

MONTEIR0, C. A. F. Por um Suporte Teórico e Prático para Estimular Estudos Geográficos de Clima Urbano no Brasil. Geosul, Santa Catarina, n. 9, p. 6-17, 1991.

RAMIRES, J. C. L. O Processo de Verticalização das Cidades Brasileiras. Boletim de Geografia, Maringá, v. 35, n. 2, p. 97-105, 1998.

SILVA, A. M. P. O Processo de Reorganização Espacial da Hotelaria do Recife: Concentração em Boa viagem e marginalização da área central. Dissertação de Mestrado em Geografia Programa de Pós Graduação em Geografia, Universidade Federal de Pernambuco, Recife, 2007. $215 f$.

DUMKE, Eliane Müller Seraphim. Clima urbano/conforto térmico e condições de vida na cidade: uma perspectiva a partir do aglomerado urbano da região metropolitana de Curitiba (AU$R M C$ ). 2007. 429 f. Tese (Doutorado) - Curso de Programa de Doutorado em Meio Ambiente e Desenvolvimento, Universidade Federal do Paraná, Curitiba, 2017. Disponível em: <https://acervodigital.ufpr.br/handle/1884/12 033>. Acesso em: 04 abr. 2018. 
NÓBREGA, Ranyére Silva; LEMOS, Thiago Verçosa da Silva. 0 microclima e o (des)conforto térmico em ambientes abertos na cidade do Recife. Revista de Geografia (UFPE), Recife, v. 28, n. 1, p.93-109, 03 jun. 2011. Quadrimestral. Disponível em: <https://periodicos.ufpe.br/revistas/revistageo grafia/article/view/228942>. Acesso em: 05 abr. 2018.

RIBEIRO, A. G. As escalas do clima. Boletim de Geografia Teorética. Rio Claro, n. 23, v. 44-46, 1993. p.288-294.
PEREIRA, G. A natureza (dos) nos fatos urbanos: produção do espaço e degradação ambiental. In: SANTOS, M. R. A. (coord.). Desenvolvimento $e$ meio ambiente: cidade $\mathrm{e}$ ambiente urbano. Curitiba: UFPR, 2001, v. 3. p.40

SILVA, Luciana Helena. A verticalização do espaço urbano: o caso do bairro do Prado Recife/PE. Dissertação de Mestrado. Departamento de Ciências Geográficas. Universidade Federal de Pernambuco. 106p. 2008. 